\title{
Percepções de profissionais de enfermagem de um hospital geral sobre a intervenção com Reikt
}

Perceptions of nursing professionals from a general hospital about Reiki intervention*

Percepciones de los profesionales de enfermería de un hospital general sobre la intervención de Reiki*

\section{Josane Rosenilda da Costa ${ }^{\mathrm{I}}$, Diéssica Roggia Piexak ${ }^{\mathrm{II}}$, Fátima Helena do Espírito Santo ${ }^{\mathrm{III}}$, Stefanie Griebeler Oliveira $^{\mathrm{IV}}$, Rosane Gonçalves Nitschkev , Sonia Silva Marcon ${ }^{\mathrm{VI}}$}

Resumo: Objetivo: identificar as percepções de profissionais de enfermagem sobre a sua participação em uma intervenção com Reiki. Método: pesquisa qualitativa que envolveu intervenção constituída por seis sessões semanais de Reiki, realizadas entre setembro de 2019 a março de 2020 com 14 profissionais de enfermagem atuantes em um hospital geral no Noroeste do Paraná. Os dados foram coletados mediante entrevista semiestruturada e submetidos à análise de conteúdo modalidade temática. Resultados: participaram seis enfermeiras e oito técnicas de enfermagem, que relataram um quadro de bem-estar, melhora no padrão de sono e da autoestima, aumento da tranquilidade, mudança de atitudes e redução de sintomas de dor e irritabilidade. Conclusão: as profissionais de enfermagem perceberam que a intervenção com Reiki promoveu equilíbrio físico e emocional, foi efetiva na redução de dores e distúrbios emocionais, trouxe benefícios para si no âmbito individual e familiar, com repercussões positivas nas relações de trabalho.

Descritores: Reiki; Terapias complementares; Enfermagem; Profissionais de enfermagem; Promoção da Saúde; Enfermagem holística

Abstract: Objective: to identify the perceptions of nursing professionals about their participation in an intervention with Reiki. Method: qualitative research involving intervention consisting of six weekly Reiki sessions, conducted between September 2019 and March 2020 with 14 nursing professionals working in a general hospital in northwestern

\footnotetext{
${ }^{\text {I } E n f e r m e i r a, ~ d o u t o r a ~ e m ~ e n f e r m a g e m, ~ C e n t r o ~ U n i v e r s i t a ́ r i o ~ I n g a ́ ~-~ U N I N G A ́, ~ M a r i n g a ́, ~ P a r a n a ́, ~ B r a s i l . ~ E-m a i l: ~ j o s a n e r c @ g m a i l . c o m, ~ O r c i d: ~}$ https://orcid.org/0000-0003-0369-977X

II Enfermeira, doutora, Universidade Federal do Rio Grande - FURG, Rio Grande, Rio Grande do Sul, Brasil. E-mail: diessicap@yahoo.com.br, Orcid: https://orcid.org/ 0000-0002-3374-7843

III Enfermeira, doutora, Universidade Federal Fluminense - UFF, Rio de Janeiro, Brasil. E-mail: fatahelens@gmail.com, Orcid: https://orcid.org/0000-0003-4611-5586

IV Enfermeira, doutora, Universidade Federal de Pelotas - UFPel, Pelotas, Rio Grande do Sul, Brasil. E-mail: stefaniegriebeleroliveira@gmail.com, Orcid: https://orcid.org/0000-0002-8672-6907

V Enfermeira, doutora, Universidade Federal de Santa Catarina - UFSC, Florianópolis, Santa Catarina, Brasil. E-mail: rosanenitschke@gmail.com, Orcid: https://orcid.org/0000-0002-1963-907X

VI Enfermeira, doutora, Universidade Estadual de Maringá - UEMPSE, Maringá, Paraná, Brasil. E-mail: soniasilva.marcon@gmail.com, Orcid: https://orcid.org/0000-0002-6607-362X

* Extraído da tese "Promoção a saúde de profissionais de enfermagem através de intervenção com Reiki”, Programa de Pós-Graduação em Enfermagem, Universidade Estadual de Maringá, 2021.
} 
Percepções de profissionais de enfermagem de um hospital geral sobre a intervenção com... $\mid 2$

Paraná. Data were collected through semi-structured interviews and submitted to thematic content analysis. Results: six nurses and eight nursing technicians participated, who reported a picture of well-being, improvement in sleep pattern and self-esteem, increased tranquility, change of attitudes and reduced symptoms of pain and irritability. Conclusion: the nursing professionals realized that the intervention with Reiki promoted physical and emotional balance, was effective in reducing pain and emotional disorders, brought benefits for themselves in the individual and family spheres, with positive repercussions on work relationships.

Descriptors: Therapeutic touch; Complementary therapies; Nursing; Nurse practitioners; Health promotion; Holistic nursing

Resumen: Objetivo: identificar las percepciones de los profesionales de enfermería sobre su participación en una intervención con Reiki. Método: investigación cualitativa que involucró una intervención consistente en seis sesiones semanales de Reiki, realizadas entre septiembre de 2019 y marzo de 2020 con 14 profesionales de enfermería trabajando en un hospital general en el noroeste de Paraná. Los datos fueron recolectados a través de entrevistas semiestructuradas y sometidos a análisis de contenido temático. Resultados: participaron seis enfermeros y ocho técnicos de enfermería, quienes relatan un cuadro de bienestar, mejoría en el patrón de sueño y autoestima, aumento de la tranquilidad, cambio de actitudes y reducción de los síntomas de dolor e irritabilidad. Conclusión: los profesionales de enfermería se dieron cuenta de que la intervención con Reiki promovió el equilibrio físico y emocional, fue efectiva en la reducción del dolor y los trastornos emocionales, trajo beneficios para sí mismos en las esferas individual y familiar, con repercusiones positivas en las relaciones de trabajo.

Descriptores: Tacto terapéutico; Terapias complementarias; Enfermería; Enfermeras practicantes; Promoción de la Salud; Enfermería holística

\section{Introdução}

Os profissionais de enfermagem que atuam em hospitais, muitas vezes, experimentam condições inadequadas e estressantes decorrentes da carga excessiva de trabalho, com elevadas responsabilidades, tanto no cuidado direto quanto nas questões gerenciais, atividades repetitivas e ritmo acelerado de prestação de cuidados. Além disso, são expostos ao risco de desenvolver doenças osteomusculares ou contrair doenças infectocontagiosas. Isto pode predispor ao desgaste físico, mental e emocional, comprometendo sua saúde, qualidade de vida e desempenho profissional. ${ }^{1-3}$

A vulnerabilidade desses profissionais foi atestada em estudo no interior do estado de São Paulo, o qual constatou que $61,2 \%$ dos 86 profissionais de uma unidade de emergência citaram ao menos uma lesão ou doença com diagnóstico médico. 59,6\% possuíam dois ou mais problemas de saúde, com predominância de lesões por acidente e doenças do sistema musculoesquelético. ${ }^{4}$

Para além de problemas físicos, a presença daqueles de natureza psicológica e relacionados 
ao estresse ocupacional em trabalhadores de enfermagem foram evidenciados. ${ }^{2,5-6}$ Esses aspectos apontam a necessidade de avaliar as condições de trabalho e reorganizar/repensar aquelas que contribuem para o adoecimento desses profissionais, ${ }^{6}$ de modo a propor intervenções de promoção da saúde com uma abordagem integral, mediante a implementação de medidas institucionais de prevenção, com foco, sobretudo, na valorização e no fortalecimento do apoio social no trabalho. ${ }^{2}$

Destaca-se que o diagnóstico de enfermagem “Campo de Energia Desequilibrado" é definido pela North American Nursing Diagnosis Association ${ }^{7}$ como a ruptura no fluxo vital de energia humana que costuma ser um todo contínuo, único, dinâmico, criativo e não linear. Assim, inúmeras são as possibilidades de intervenção aos profissionais de enfermagem, no ambiente de trabalho, com destaque para as Práticas Integrativas e Complementares em Saúde (PICS). No contexto atual, o Reiki, na condição de uma dessas práticas, foi sugerido aos profissionais de enfermagem como uma das estratégias possíveis visando à promoção da saúde mental e o enfrentamento da COVID-19. ${ }^{8}$

O Reiki é uma das práticas terapêuticas institucionalizadas na Política Nacional de Práticas Integrativas e Complementares (PNPIC) no Sistema Único de Saúde (SUS). ${ }^{9}$ Trata-se de um sistema milenar de cuidado que utiliza a imposição das mãos - por meio da aproximação ou o toque sobre o corpo - de um profissional capacitado no Método de Reiki de Mikao Usui, para canalizar a energia vital, no intuito de estimular os mecanismos naturais de recuperação da saúde e promover o equilíbrio energético necessário ao bem-estar físico e mental. ${ }^{10}$

Cabe destacar que, em relação às demais profissões, a enfermagem foi pioneira ao estabelecer e reconhecer as PICS como especialidade ou qualificação. A Resolução n n 581/2018 é a que, atualmente, reconhece o Reiki como uma das especialidades do Enfermeiro na área das Práticas Integrativas e Complementares. ${ }^{11}$ Diante do exposto, tem-se como objetivo: identificar as percepções de profissionais de enfermagem sobre a sua participação em uma intervenção com Reiki.

\section{Método}


Percepções de profissionais de enfermagem de um hospital geral sobre a intervenção com... $\mid 4$

Trata-se de um estudo descritivo, de abordagem qualitativa, realizado em um hospital escola no Noroeste do Paraná. À época da intervenção, esta instituição possuía 104 leitos destinados à internação em diferentes áreas e é referência para atendimento em média e alta complexidade para os trinta municípios que integram a 15ª Regional de Saúde do estado.

Os informantes foram 14 profissionais de enfermagem que participaram de uma intervenção constituída por seis sessões semanais, com o método Reiki de Mikao Usui aplicado por enfermeira capacitada para o nível $3 \mathrm{~A}$, o qual a habilita a fazer uso dele em grandes multidões. ${ }^{10}$

O número e a duração das sessões foram estabelecidos a partir do que o método propõe ${ }^{10}$ e do propósito da pesquisa. Na literatura foram encontrados estudos que realizaram desde uma até oito sessões, com periodicidade diversa, normalmente uma a duas vezes na semana. As sessões semanais foram realizadas às quartas-feiras, manhã e tarde, dada a disponibilidade do local. Ressalta-se que eram agendadas somente três sessões por período (seis por dia), pois antes do início ou ao final das mesmas era disponibilizado um tempo para conversas informais, quando as participantes tinham oportunidade de falar sobre suas angústias e sofrimentos.

As sessões de Reiki foram realizadas no período de setembro/2019 a março/2020, com duração média de 30 minutos, e ocorreram em sala privativa, no hospital, devidamente preparada de modo a tornar o ambiente confortável e aconchegante (maca, música relaxante, aromatização, e luz apenas do difusor de aromas). Para receber o Reiki, as participantes eram convidadas a se deitar na maca, em decúbito dorsal, e, caso o desejassem, o corpo era coberto por um lençol. Inicialmente, eram orientadas para que inspirassem e expirassem profundamente de olhos fechados para favorecer o relaxamento e a concentração. Então, era iniciada a aplicação energética, mediante a imposição das mãos sobre as posições da cabeça, chakras $^{11}$ e em locais que apresentassem alguma queixa de algia.

As participantes foram informadas sobre a intervenção mediante cartazes afixados nos setores do hospital e mensagem enviada, via Whats $A p p^{\circledR}$, pelas chefias aos grupos de trabalho, 
contendo número de contato telefônico da pesquisadora tanto para obter maiores informações relativas à prática quanto para agendar horário. Os critérios de inclusão previamente definidos foram: profissionais de enfermagem, de ambos os sexos, atuantes em qualquer setor do hospital, independente do tempo. Como critério de exclusão definiu-se a ausência a mais de duas sessões consecutivas de Reiki ou impossibilidade de participar da entrevista final. Um total de 35 profissionais entraram em contato, via telefone e/ou WhatsApp ${ }^{\oplus}$, mas apenas 16 declararam disponibilidade para comparecer à instituição fora do horário de trabalho.

Os dados foram coletados mediante duas entrevistas semiestruturadas, individuais, gravadas em áudio após consentimento dos participantes: uma antes do início da intervenção, e outra uma semana após o seu término. Todas as entrevistas, com duração média de 30 minutos, foram feitas pela pesquisadora principal e no mesmo ambiente onde as sessões de Reiki eram realizadas. Vale ressaltar que, devido à suspensão de atividades de pesquisa na instituição por causa da Pandemia da Coronavirus Disease 2019 (COVID-19), a entrevista pós-intervenção com as participantes do último grupo ocorreu em seus domicílios, respeitando-se as medidas de segurança, e após o prazo inicialmente previsto (com dois meses de atraso, aproximadamente).

Os registros em um diário de campo, relativos às conversas informais para saber como a participante havia se sentido desde o último encontro, também constituíram o corpus de análise. E nas entrevistas semiestruturadas realizadas antes da intervenção foi utilizado um roteiro constituído de duas partes: na primeira constavam questões sociodemográficas, profissionais e condições de saúde; na segunda, itens do objeto em estudo: "Fale-me sobre sua história, como você é na sua casa e no seu trabalho? O que você sabe sobre o Reiki? Por que quer participar da intervenção? O que você espera? E a entrevista realizada após a última sessão foi guiada pela seguinte questão: “Conte-me: como está se sentindo consigo, na sua casa, no seu trabalho?”

As participantes compuseram três grupos, os quais foram implementados de forma consecutiva, ou seja, um novo grupo era iniciado somente após o término do anterior. Ressalta-se 
Percepções de profissionais de enfermagem de um hospital geral sobre a intervenção com... 6

que das 16 profissionais que participaram das sessões de Reiki, duas foram excluídas da análise do estudo por não terem realizado a entrevista final. Ambas pertenciam aos grupos de risco e não puderam receber a pesquisadora em suas residências e não sabiam lidar com internet (WEB) para a realização de uma entrevista on-line.

Os dados coletados foram transcritos na íntegra e submetidos à análise de conteúdo, modalidade temática. Para tanto, inicialmente foi realizada leitura flutuante dos dados, seguida de leitura em profundidade para exploração do material. Os temas emergentes identificados foram agrupados por semelhança e, posteriormente, organizados em categorias. ${ }^{12}$

No desenvolvimento do estudo foram seguidos todos os preceitos éticos preconizados pela Resolução 466/2012 do Conselho Nacional de Saúde. O projeto de pesquisa foi aprovado pelo Comitê de Ética em Pesquisa com Seres Humanos da instituição signatária (CAAE: 17865719.8.0000.0104) em 05/09/2019. Todas as participantes foram informadas sobre os objetivos e procedimentos de pesquisa e assinaram o Termo de Consentimento Livre e Esclarecido. Para preservar-lhes o anonimato, as participantes foram identificadas com a letra $\mathrm{P}$, seguida do número indicativo da ordem de participação no estudo.

\section{Resultados}

As 14 participantes, todas do sexo feminino, tinham idade de 27 a 59 anos, sendo 13 católicas. Apenas uma não tinha companheiro e uma era reikiana nível I não praticante. Das seis enfermeiras, todas são especialistas, duas são doutorandas e uma mestranda. Quanto às oito técnicas de enfermagem, todas possuem nível superior: três são graduadas em Enfermagem, três em Gestão em Saúde, uma em Administração e uma em Pedagogia. O tempo de serviço no hospital em estudo variou de cinco a 25 anos. Elas atuavam em setores diversos: quatro na Unidade de Terapia Intensiva Neonatal (UTIN), duas na Central de material, duas no Banco de Leite Humano (BLH), duas na Clínica Obstétrica/Ginecológica (GO) e uma nos setores de Pronto Atendimento, Banco de Sangue, Clínica Médica e Clínica Cirúrgica. 
Todas possuíam algum problema de saúde: quatro referiram ter Fibromialgia (FM); duas, dores osteomusculares incapacitantes; uma, Diabetes Mellitus tipo 1; e cinco apresentavam excesso de peso. Ademais, quatro utilizavam medicamentos antidepressivos há mais de seis meses, uma referiu ser compradora compulsiva e outra referiu ansiedade elevada. Todas apresentavam pelo menos um dos seguintes sintomas: quadro depressivo e ansioso não diagnosticado, insônia ou dificuldades para dormir. Uma participante não tomava qualquer medicação de uso contínuo, e três realizavam alguma forma de atividade física: corrida, academia e caminhada.

Motivações para a busca pelo "projeto de Reiki"

As motivações para a participação no projeto foram diversas e incluíram conhecer a terapia e buscar soluções para as queixas de natureza física, emocional, familiar ou mesmo laboral e por acreditarem que o Reiki poderia contribuir para melhorar seus problemas físicos e emocionais e auxiliá-las a lidar com tais questões em suas vidas.

\footnotetext{
Eu não durmo bem, eu trabalho muito, e então eu acho também que o estresse no trabalho me adoece sabe, eu sempre estou doente. (P3)

Vim procurar por conta da minha história, meus conflitos, conflitos familiares e como eles me afetam em tudo. (P4)

Olha, eu vim para conhecer, o que é isso [...] o Reiki, soube do projeto[...] então eu vim. (P13)

Tem muito problema no setor, muito mesmo, a gente vê as coisas erradas [...] mas quem tem que atuar? A chefia, e a chefia [longa pausa]. (P1)

Eu sou a pessoa que está sempre para traz sabe, no serviço, sempre acabo tudo bem depois [...] as vezes eu olho [...]queria melhorar. (P10)

Vim conhecer, [...] conheço muitas terapias, e vim conhecer o Reiki. (P7)
}

Dentre as participantes, seis referiam ter procurado o projeto devido à presença de dores crônicas decorrentes, por exemplo, de FM e hérnia de disco, as quais, além de limitar suas atividades no trabalho, prejudicavam sua convivência social.

Tenho muita dor no quadril, ando a base de remédios. (P13)

Tenho muitas dores, da fibromialgia, eu incho demais as articulações, dói muito, geralmente de manhã, ao acordar. Até acordo mais cedo, pois tenho que ensaiar para sair da cama, começo a movimentar os dedos lentamente, depois as mãos, até conseguir levantar e sair da cama. (P10)

Minhas costas, tenho muita dor, por causa da fibromialgia, tem dias que quase não consigo caminhar, movimentar normalmente, é um peso gigantesco, as vezes acho que não vou 
Percepções de profissionais de enfermagem de um hospital geral sobre a intervenção com... $\mid 8$

conseguir carregar. (P7)

Tenho muitas dores, tenho hérnia cervical, muitas dores mesmo, eu trabalho a base de medicação forte, não consigo ficar sem, não movimento o braço se não tomar analgésico. (P3)

Eu não conseguia realizar as atividades na UTI [...], não tinha mais força, e a dor ainda atrapalha muito [...], então fui remanejada de setor [ar triste], mas não gosto, eu gosto mesmo é de lidar com o paciente [...] para mim é terrível, sofro muito. (P7)

Contudo, com o passar do tempo (após duas ou três sessões), algumas profissionais relataram a presença de quadro depressivo e o uso de medicação controlada para essa condição, além de outras disfunções emocionais.

Vivo a base de remédio para poder aguentar [...]. Fico nervosa quando percebo pessoas encostando serviço. (P1)

Sou crítica no trabalho, $[. .$.$] ainda mais crítica, mais agitada e mais implicante com$ as coisas em casa [risos]. (P10)

Percebo muita falta de interesse, com o trabalho, com o outro dia a colega ficou $2 \mathrm{~h} 15$ no café, a sala lotada [...] isso me adoece. (P3)

Percebo assim, [...], tem às vezes um problema, que é pequeno sabe, que poderia se resolver,

[...] ser resolvido na verdade. E quando vejo, tomou uma proporção tão grande, que não precisava, no fim, tudo acaba em grandes conflitos. (P5)

Os relatos desta categoria mostram que a procura pela intervenção com Reiki foi motivada, inicialmente, pelo desejo de obter melhorias de queixas físicas, sobretudo dores. Porém, nas conversas informais mantidas no decorrer da pesquisa, houve relato dos conflitos no ambiente laboral e na vida em família, decorrentes de condições emocionais fragilizadas.

Conhecimentos prévios sobre o Reiki

As participantes do estudo, de modo geral, informaram ter pouco conhecimento sobre o Reiki.

Eu trabalhei 18 anos em uma clínica de terapias integrativas, então eu conheço um pouco sobre as práticas, nunca estudei, mas conheço. $(\mathrm{P} 1)$

Eu dei uma lida rápida antes de vir, então eu vi o básico sobre o Reiki que não está relacionado a religião. É uma energia neutra que muitas pessoas têm preconceito ainda em receber e reconhecer o Reiki [...] por ser uma terapia que não é palpável. (P2)

Reiki não conheço, conheço outras terapias, imagino que seja como a meditação, [...] eu faço meditação. (P3)

Contudo, o pouco que conheciam sobre o Reiki lhes permitia ter uma atitude positiva em relação ao mesmo e a associá-lo à promoção do equilíbrio e bem-estar.

Não sei exatamente o que é[...] está relacionado à religião? Sei que é algo bom, para ajudar a 
equilibrar o corpo, relaxar. (P5)

Não sei o que é, sei que é bom, que faz bem para a saúde [...] vi as meninas comentando, então eu vim [...]. Algo que mexe com as energias, sei que faz bem, nunca li sobre. (P13)

Eu faço meditação transcendental e tem me ajudado muito, então eu acho que é meio parecido. $(\mathrm{P} 11)$

Constata-se que o fato de as participantes serem profissionais da área de enfermagem lhes permite compreender que o estado de saúde de uma pessoa é resultante da relação de equilíbrio do organismo. E que as demandas não atendidas, em qualquer fase da vida, aliadas ao desgaste físico e mental no ambiente de trabalho, podem resultar em desequilíbrio e, consequentemente, em doença física ou emocional, com repercussões no desempenho das atividades de vida diária e laborais.

Sou muito irritada no ambiente de trabalho, gosto tudo do meu jeito [...] controladora, inquieta com marido e filho [...] briguenta, muito ansiosa [ênfase]. É ansiosa, sim, sou ansiosa, muito ansiosa. (P5)

O trabalho me desgasta muito [...] me ligam qualquer hora e eu vou, não sei dizer não, eu vou [...] mas sofro, fico nervosa, choro depois [choro intenso], cada vez fico mais nervosa [...] em casa, fico irritada, tenho ainda o mestrado, mal consigo estudar. (P3)

Ando tendo problemas com o sono [...] sou muito hiperativa, trabalho muito me desgasto bastante. Eu sou muito agitada e sou muito irritada também lógico. (P13)

Eu não durmo bem, eu trabalho muito, e então eu acho também que o estresse me adoece sabe, eu sempre estou doente. ( $\mathrm{P} 2)$

Foi possível identificar que, de modo geral, as participantes não tinham conhecimento prévio do Reiki, mas buscaram a intervenção por acreditar que poderia ajudá-las de alguma forma.

Melhoria na vida percebida a partir da intervenção com Reiki

Ao longo da intervenção, após as primeiras sessões, as participantes passaram a relatar uma autopercepção positiva na forma de se relacionarem consigo, com os familiares e com o trabalho.

Estou me sentindo mais leve mais viva. Eu me achei. Eu consigo dizer os nãos que eu preciso, consigo falar, não me maltratar [chorando muito emocionada]. Conseguir falar, me posicionar. Isso é maravilhoso. (P2)

Hoje eu sei que as minhas atitudes estão diferentes de antes [...]. E eu até começo a observar coisas diferentes em mim e no mundo. (P9)

Estou cuidando de mim. Você viu que eu pintei o cabelo? Fazia anos que eu não me olhava, não me cuidava. Falei com meu colega de plantão: "A gente não vai conseguir mudar o mundo ou mudar todas as pessoas, mas a gente precisa mudar a gente, mudar aqui" [chorando coloca mão no coração]. E a gente [...] a gente vai dar o nosso melhor. $E$ vai ser assim vai ser assim que a gente vai fazer. Ele até riu: "Nossa o que está acontecendo com você?!”[risos]. (P3)

Após o término das sessões foram relatadas melhoras importantes de alguns sintomas - 
Percepções de profissionais de enfermagem de um hospital geral sobre a intervenção com... $\mid 10$

sobretudo em relação à qualidade do sono e ao alívio da dor - que eram experenciados há anos, e que não apresentavam melhora nem mesmo com tratamentos alopáticos.

Está uma benção, estou dormindo muito bem, isso valeu muito a pena, deitar e dormir [...]. Muito bom, valeu muito a pena participar. (P4)

Melhorou muito, eu mal conseguia me deitar na maca, tamanha dor, hoje deitei e consegui relaxar. (P2)

Foi muito bom [...] foi o que me sustentou no decorrer da descoberta do diagnóstico, da Esclerose, foi o que me ajudou a não desistir[emocionada]. (P8)

Além disso, duas participantes mencionaram a procura e a realização da iniciação no método Reikiapós a participação na intervenção.

Eu fiz iniciação, fiz com a minha amiga que é mestre de Reiki [...] é tão forte isso. (P12)

Foi muito bom, eu comecei a fazer muitas coisas assim, integrativas, estou usando óleos essenciais, comecei a meditação também e agora fiz a iniciação no Reiki[risos]. (P8)

Contudo, duas participantes demonstraram dificuldade em aceitar a melhora alcançada e associá-la à realização das sessões de Reiki.

Minhas dores melhoraram, sim, [...] mas eu também fui no reumatologista, voltei a fazer acompanhamento, ele trocou a medicação, pode ser isso não é?(P10)

Eu melhorei um pouco, consigo lidar melhor com as questões do trabalho, da familia [...], mas acho que é mais por eu ter evoluído mesmo, não sei, não considero que foi o Reiki. Não acredito que tem este poder, acredito que foram nossas conversas, sua escuta, as atividades [...]. (P14)

Observou-se que as principais mudanças percebidas pelas participantes estão relacionadas à redução de dores e à melhoria do sono, e este se tornou mais profundo e reparador.

\section{Discussão}

Quanto à caracterização das participantes, todas são mulheres, possuem alguma condição de saúde e fazem uso contínuo ou frequente de medicações: para dor, insônia, antidepressivo ou relaxante muscular. Além do fato de as mulheres comporem a maioria da força de trabalho da enfermagem, por questões históricas e socialmente construídas elas ainda são as principais responsáveis pelos cuidados com a casa e com os filhos, mesmo quando trabalham fora e, inclusive, quando possuem dois vínculos empregatícios, o que contribui sobremaneira para o surgimento de queixas álgicas e somáticas. ${ }^{2-3}$ 
Esse cenário contribui para o desenvolvimento e para o agravamento do estresse ocupacional crônico, considerado determinante dos transtornos depressivos e que, frequentemente, se expressa em cefaleias, irritabilidade, distúrbios de sono, dores e sobrepeso, ${ }^{13-14}$ sintomas estes relatados pelas participantes. Destaca-se que esse mesmo perfil de queixas álgicas e de uso de medicamentos foi observado entre os profissionais de enfermagem de um hospital geral em São Paulo que participaram de intervenção com a auriculoterapia para a redução do estresse e da dor. ${ }^{15}$

É importante salientar que as participantes do presente estudo tinham uma atitude positiva em relação ao Reiki, mas pouco conhecimento sobre o mesmo. Destarte, embora o Reiki seja uma prática milenar, ainda é pouco conhecido e utilizado. No Brasil, por exemplo, entrou para o rol das PICS na PNPIC somente no ano de $2017 .^{9}$

Estudo realizado em dois municípios de Goiás e um de Minas Gerais constatou que dos 118 profissionais de saúde de nível superior atuantes no SUS, apenas um afirmou não ter nenhum conhecimento sobre as PICS. Em contrapartida, 19 deles, conhecedores da PNPIC, as consideravam importantes - para a profissão e para o SUS, e que as mesmas deveriam ser inseridas na graduação. ${ }^{16}$ Estudo de revisão sobre essas práticas ressaltou a necessidade de investir na formação desses trabalhadores da saúde desde a graduação. Os autores desse estudo consideraram que a introdução desta temática nos currículos pode favorecer a ação cotidiana em saúde, pois, embora reconheçam a contribuição das PICS para a promoção, prevenção e tratamento em saúde, esses profissionais não as utilizam e, além disso, sentem-se inseguros e com pouco conhecimento para indicá-las. ${ }^{17}$

Em relação aos motivos de procura pela participação no Projeto de Reiki, observou-se que as queixas das participantes, em um primeiro momento, eram circunscritas às manifestações físicas e estavam ligadas ao cotidiano de trabalho no qual o profissional está inserido, que, muitas vezes, está repleto de fatores causadores de estresse e sofrimento, por exemplo, trabalhar com uma equipe despreparada. ${ }^{3}$ Essa realidade é agravada pelas limitações estruturais nos serviços, pela falta de recursos humanos, pela sobrecarga e pela jornada de trabalho exaustiva, pelo duplo vínculo 
empregatício e, muitas vezes, pela falta do devido reconhecimento profissional. ${ }^{3}$

Destarte, a presença de sintomas relacionados ao estresse ocupacional é comum entre trabalhadores da saúde, sobretudo os de enfermagem. Estudo realizado em um hospital de Santa Catarina identificou que $71 \%$ deles apresentavam algum distúrbio do sono,${ }^{14}$ mas em um Serviço de Atendimento Médico de Urgência (SAMU) essa prevalência atingiu $56 \% .{ }^{18}$ Ressalta-se que a privação do sono pode afetar a saúde física e mental e influenciar a qualidade do trabalho de profissionais de enfermagem. ${ }^{5}$

Os benefícios do Reiki para esses tipos de queixas são ressaltados em seus propósitos: restabelecer e harmonizar a qualidade do sono das pessoas, e também seu bem-estar nos âmbitos físico, emocional, mental e espiritual. ${ }^{1}$ Destaca-se que, de acordo com os relatos das participantes, a presença de dores crônicas e o desejo de aliviá-las constituiu, a princípio, o principal motivo que as levou a participar da intervenção. Isso é coerente com a condição de saúde das mesmas, pois quatro delas tinham diagnóstico de FM, uma tinha hérnia cervical, e a outra, artrose no quadril.

Na população em geral, a prevalência de FM é de 5\%, e $85 \%$ das pessoas acometidas são do sexo feminino. ${ }^{19}$ Por sua vez, a dor crônica advinda da FM afeta a qualidade de vida e o labor das mulheres, afastando-as do convívio social devido ao sofrimento emocional, físico e psíquico. ${ }^{20}$ Isso foi observado nas participantes, e uma delas teve que ser transferida de setor, fato que a entristecia e lhe causava sofrimento psíquico.

Intervenções com Reiki têm sido realizadas em diferentes populações, e os propósitos e resultados positivos quase sempre são observados na maioria dos participantes, seja na redução da dor oncológica ${ }^{21}$ ou na atenuação de sintomas associados ao sistema nervoso: depressão, ${ }^{22}$ estresse, distúrbios do sono, fadiga e ansiedade e aumento da sensação de relaxamento. ${ }^{15,23}$

Em relação aos profissionais da área da saúde, as intervenções com Reiki ainda são incipientes, mas já demonstraram resultados positivos, por exemplo, no caso de enfermeiras com Síndrome de Burnout. ${ }^{24}$ Além disso, a intervenção favoreceu o autocuidado com melhora no manejo do estresse diário e no fortalecimento da autoestima em enfermeiros ${ }^{25}$ e proporcionou relaxamento 
e redução da irritabilidade em trabalhadores de uma Equipe de Estratégia Saúde da Família. ${ }^{26}$

Destarte, o Reiki pode ser uma alternativa para esses profissionais, pois se apresenta como uma técnica complementar que atua no restabelecimento e harmonização do organismo, o que, por sua vez, repercute na melhoria da qualidade do padrão de sono e promove bem-estar no âmbito físico, emocional, mental e espiritual. ${ }^{10}$ Ressalta-se que estudo de revisão da literatura apresentou evidências de que o Reiki é mais eficaz do que o placebo para diminuir a dor, a ansiedade e a depressão e para aumentar a autoestima e a qualidade de vida das pessoas com problemas crônicos de saúde. ${ }^{27}$ Nesse sentido, segundo a percepção das participantes, constatou-se que as dores foram amenizadas com a aplicação do Reiki, dado que corrobora resultados de outros estudos, em que foi observada a melhora das queixas de dor e no bem-estar em pacientes com dores crônicas generalizadas $^{28}$ e também em pacientes submetidos a cirurgias ortopédicas. ${ }^{29}$

Após as sessões de Reiki, as participantes relataram melhora dos sintomas, apresentados antes do início da intervenção: dificuldade para dormir, cansaço físico e mental, dores, melhora no relacionamento com a família, com o trabalho e consigo. Acerca das percepções associadas ao bemestar geral, ao autocuidado e à motivação diária, observou-se que elas descreveram melhorias, as quais, de modo geral, foram relacionadas à participação na intervenção com Reiki.

Os resultados apresentados são explicáveis pela física quântica, na qual seu precursor, Albert Einstein, demonstrou e reconheceu alguns fenômenos relacionados a essa terapia que, há algum tempo, não era reconhecida com caráter científico. A explicação para tais benefícios plasma-se nos conceitos de frequência vibracional. ${ }^{30}$

O Reiki, por meio de frequência mais alta de vibração, dissolve bloqueios energéticos quando a energia do terapeuta percorre os chakras da pessoa, proporcionando a harmonização gradual e constante. ${ }^{1}$ Desse modo, ao se entender que o ser humano é um campo de energia, é possível afirmar que sempre que ela é afetada de modo consciente e intencional pelo terapeuta, todo o sistema é afetado de forma positiva. ${ }^{30}$ 
Percepções de profissionais de enfermagem de um hospital geral sobre a intervenção com... | 14

Foi observada uma postura mais positiva em relação a si, à família, ao trabalho e à vida de modo geral ao longo das sessões e não somente ao final da intervenção. Nos momentos iniciais ou finais dos encontros, as participantes relataram situações do cotidiano que demonstravam mudança de atitude. É possível que o fato de as participantes se mostrarem receptivas e sensíveis ao Reiki esteja relacionado à percepção e à descrição de efeitos positivos caracterizados pela sensação de bem-estar, alívio, relaxamento e tranquilidade logo após cada sessão.

Ao final da intervenção as participantes referiram conseguir lidar de maneira adequada e equilibrada com os conflitos do cotidiano relacionados ao autocontrole, aos problemas familiares e ao trabalho, o que lhes permitia contemplar os aspectos positivos da vida. Isto se deve ao fato de o Reikiser um processo energético que atua harmonizando o ser humano de modo integral. ${ }^{10}$

Nota-se, aqui, a importância de compreender que, no ato de cuidar, também é preciso cuidar do campo energético, pois, assim, o profissional facilita o restabelecimento da pessoa nas dimensões física, emocional e espiritual. ${ }^{25}$ Isso nos remete ao cuidar aliado ao uso do Reiki, aos seus benefícios e às possibilidades de utilização, o que explicita que as medidas de promoção do bemestar espiritual precisam ser incluídas no plano de cuidados de enfermagem. ${ }^{7}$

Assim, o presente estudo coaduna-se com as recomendações do Ministério da Saúde e com a Política Nacional de Promoção à Saúde (PNPS), a qual aconselha a utilização de práticas de cuidado que atendam o ser humano, e levem em consideração sua multidimensionalidade. Conforma-se também com a Política Nacional das Práticas Integrativas e Complementares em Saúde (PNPICS), considerando-se que o Reiki é integrante dela. ${ }^{9}$

Cabe destacar que duas participantes demonstraram dificuldade em aceitar e em atribuir ao método Reiki a melhora alcançada. Isso, provavelmente, se deva ao fato de valorizarem a medicina alopática e ao desconhecimento sobre o Reiki. Por outro lado, duas participantes mencionaram a procura e a realização da iniciação no método Reiki após a participação no projeto. É importante enfatizar que o Reiki é facilmente adaptável à prática de enfermagem em diversos ambientes de 
cuidado, podendo também fornecer suporte aos próprios praticantes.

Ressalta-se a importância de incluir no ensino de graduação em Enfermagem conteúdos teóricocientíficos sobre as estratégias e metodologias assistenciais que possam favorecer uma assistência mais integral, dentre as quais as diferentes modalidades de PICS. Nessa inclusão, é importante salientar suas indicações, benefícios e possíveis limitações para o uso no cuidado dos pacientes e para os próprios profissionais.

Por fim, os resultados deste estudo podem servir de incentivo aos serviços e instituições de saúde para a criação de espaços terapêuticos destinados aos profissionais, sobretudo os de enfermagem, com a utilização de PICS, em especial o Reiki. Essa ação pode favorecer a saúde e o autocuidado, de modo a apoiar os enfermeiros a enfrentar as demandas cotidianas nos serviços, as quais podem acarretar desgaste físico e mental com consequente desequilíbrio e adoecimento.

Possíveis limitações do estudo referem-se à baixa adesão à proposta, resultando no número de participantes, o que pode decorrer da sobrecarga de trabalho e da dificuldade de comparecer às sessões fora do horário de expediente, conforme exigência da diretoria de enfermagem da instituição para autorizar a realização do estudo. A dificuldade decorreu do fato de a maioria dos trabalhadores de enfermagem que atuam nesse hospital possuir mais de um vínculo empregatício.

\section{Conclusão}

Os relatos das participantes permitiram apreender que elas perceberam benefícios decorrentes da participação em intervenção com Reiki, sobretudo em relação à qualidade do sono, bem-estar, melhora da autoestima, diminuição/alívio de dor crônica e expansão da consciência sobre si, a família, o trabalho e a vida em geral.

Conclui-se que os resultados demonstram melhorias no âmbito pessoal, familiar e no trabalho das participantes, e foi observada sua mobilização e seus esforços em continuar participando da intervenção e em recomendá-la a outros profissionais. Os achados podem ampliar o diálogo com a literatura corrente e reforçam a necessidade de dar continuidade à exploração do 
Percepções de profissionais de enfermagem de um hospital geral sobre a intervenção com... | 16

tema mediante a realização de intervenções com um número maior de participantes.

\section{Referências}

1. Dias CVP, Damasceno JC, Silva LVF, Rocha BM. Saúde do profissional de Enfermagem: riscos ocupacionais em ambiente hospitalar. Saúde (Santa Maria). 2020;46(2). doi: 10.5902/2236583434972

2. Santana LC, Ferreira LA, Santana LPN. Occupational stress in nursing professionals of a university hospital. Rev Bras Enferm. 2020;73(2):e-20180997. doi: 10.1590/0034-7167-2018-0997

3. Silvino MCS, Wakiuchi J, Costa JR, Ribeiro AL, Sales CA. Vivências do sofrimento moral na equipe de enfermagem. Rev Enferm UFPE On Line [Internet]. 2016 [cited 2020 set 29];10(3):1054-62. Available from: https://periodicos.ufpe.br/revistas/revistaenfermagem/article/viewFile/11058/12477

4. Bordignon M, Monteiro MI. Problemas de salud entre profesionales de enfermería y factores relacionados. Enferm Glob. 2018;17(3):435-69. doi: 10.6018/eglobal.17.3.302351

5. Takashi MH, Batista LS. Os principais fatores causadores de Estresse em profissionais de enfermagem que atuam em Unidade de Terapia Intensiva. REVISA. 2020;9(1):156-62. doi: 10.36239/revisa.v9.n1.p156a162

6. Oliveira DM, Alencar NMBM, Costa JP, Fernandes MA, Gouveia MTO, Santos JDM. Afastamento do trabalho por transtornos mentais e comportamentais entre profissionais de enfermagem. Rev Cuid (Bucaramanga). 2019 Aug;10(2):e631. doi: 10.15649/cuidarte.v10i2.631

7. Herdman TH, Kamisuru S. Diagnósticos de enfermagem da NANDA: definições e classificação 2018-2020/ NANDA International. Porto Alegre: Artmed; 2018.

8. Dal'Bosco EB, Floriano LSM, Skupien SV, Arcaro G, Martins AR, Anselmo ACC. Mental health of nursing in coping with COVID-19 at a regional university hospital. Rev Bras Enferm. 2020;73(Suppl 2): e20200434. doi: 10.1590/0034-7167-2020-0434

9. BRASIL. Ministério da Saúde. Portaria n 702, de 21 de Março de 2018. Altera a Portaria de Consolidação n⿳o 2/GM/MS, de 28 de setembro de 2017, para incluir novas práticas na Política Nacional de Práticas Integrativas e Complementares - PNPIC. Brasília, DF: Ministério da Saúde, 2018. Disponível em: http://bvsms.saude.gov.br/bvs/saudelegis/gm/2018/prt0702_22_03_2018.html. Acesso em: 28 set. 2020.

10. De’ Carli J. Reiki, amor, saúde e transformação. 7a ed. São Paulo (SP): Alfabeto; 2017.

11. CONSELHO FEDERAL DE ENFERMAGEM. Resolução COFEN № 581/2018. Atualiza, no âmbito do Sistema Cofen /Conselhos Regionais de Enfermagem, os procedimentos para registro de título de pósgraduação lato e stricto sensu concedido a enfermeiros e lista as especialidades. Diário Oficial da União: seção 1, Brasília, DF, n. 137, p. 119, 18 jul. 2018.

12. Bardin L. Análise de conteúdo. Lisboa (PT): Edições 70; 2016.

13. Leonelli LB, Andreoni S, Martins P, Kozasa EH, Salvo VL, Sopezki D, et al. Estresse percebido em profissionais da Estratégia Saúde da Família. Rev Bras Epidemiol. 2017;20(2):286-98. doi: 10.1590/19805497201700020009 
14. Batista RS, Lima AVS. Avaliação da qualidade do sono e prevalência de sintomas depressivos na equipe de enfermagem de um hospital de Santa Catarina [monografia]. Tubarão (SC): UNISUL; 2019.

15. Kurebayashi LFS, Turrini RNT, Souza TPB, Marques CF, Rodrigues RTF, Charlesworth K. Auriculotherapy to reduce anxiety and pain in nursing professionals: a randomized clinical trial. Rev Latinoam Enferm. 2017;25:e2843. doi: 10.1590/1518-8345.1761.2843

16. Gontijo MBA, Nunes MF. Práticas integrativas e complementares: conhecimento e credibilidade de profissionais do serviço público de saúde. Trab Educ Saúde. 2017;15(1):301-20. doi: 10.1590/1981-7746-sol00040

17. Sartori Dalmolin I, Heidemann ITSB. Práticas integrativas e complementares e a interface com a promoção da saúde: revisão integrativa. Cienc Cuid Saúde 2017;16(3):e-33035. doi: https://doi.org/10.4025/cienccuidsaude.v16i3.33035

18. Silva JSX, Silva RM, Cangussu DDD, Moraes Filho IM, Pérez MA, Proença MFR. Qualidade do sono dos profissionais de enfermagem do serviço móvel de atendimento de urgência. REVISA. 2019;8(3):264-72. doi: 10.36239/revisa.v8.n3.p264a272

19. Santos Junior EP, Marson PG, Nepomuceno VR. Estudo epidemiológico da fibromialgia em ambulatório municipal de reumatologia no Estado do Tocantins. Rev Cereus. 2020;12(3):259-71. doi: 10.18605/21757275/cereus.v12n3p259-271

20. Oliveira JPR, Berardinelli LMM, Cavaliere MLA, Rosa RCA, Costa LP, Barbosa JSO. O cotidiano de mulheres com fibromialgia e o desafio interdisciplinar de empoderamento para o autocuidado. Rev Gaúcha Enferm. 2019;40:e20180411. doi: 10.1590/1983-1447.2019.20180411

21. Doğan MD. The effect of reiki on pain: a meta-analysis. Complement Ther Clin Pract. 2018;31:384-7. doi: 10.1016/j.ctcp.2018.02.020

22. Medeiros SP, Oliveira AMN, Silva MRS, Freitag VL, Afonso MS, Brum AN. Integrative and additional practices: care strategy for Reiki in depression people. Res Soc Dev. 2020;9(2):e127922149. doi: 10.33448/rsd-v9i2.2149

23. Erdoğan Z, Çinar S. The effect of Reiki on depression in elderly people living in nursing home. Indian J Tradit Knowl. 2016;15(1):35-40.

24. Díaz-Rodríguez L, Arroyo-Morales M, Fernández-de-las-Peñas C, García-Lafuente F, García-Lafuente F, García-Royo C, et al. Immediate effects of Reiki on heart rate variability, cortisol levels, and body temperature in health care professionals with burnout. Biol Res Nurs. 2011;13(4): 376-82 .doi: 10.1177/1099800410389166

25. Silva Júnior EJ, Balsanelli AP, Neves VR. Care of the self in the daily living of nurses: an integrative review. Rev Bras Enferm. 2020;73(2):e20180668. doi: 10.1590/0034-7167-2018-0668

26. Freitag VL, Andrade A, Badke MR, Heck RM, Milbrath VM. A terapia do reiki na Estratégia de Saúde da Família: percepção dos enfermeiros. Rev Pesq Cuid Fundam. 2018;10(1):248-53. doi: 10.9789/2175-5361.2017.v10i1.248-253

27. McManus DE. Reiki is better than placebo and has broad potential as a complementary health therapy. Evid Based Integr Med. 2017;22(4):1051-7. doi: 10.1177/2156587217728644

28. Oliveira PM, Rodrigues BB, Cardoso RRJ, Araújo GF, Severino IGCK, Marques FF. Reiki e meditação mindfullness no manejo do paciente com dores crônicas: uma revisão de literatura. Braz J Health Rev. 
2020;3(1):1155-67. doi: 10.34119/bjhrv3n1-089

29. Baldwin AL, Vitale A, Brownell E, Kryak E, Rand W. Effects of Reiki on pain, anxiety, and blood pressure in patients undergoing knee replacement: a pilot study. Holist Nurs Pract. 2017:31(2):80-9. doi: 10.1097/HNP.0000000000000195

30. Santos JMCG, Lopes PQ. Teoria quântica e terapia vibracional, uma nova visão a ser inserida nas práticas integrativas e complementares: uma revisão da literatura. Rev Bras Práticas Integrativas Complet Saúde [Internet]. 2016 [acesso em 2020 set 15];5(5):142-76. Disponível em: https://www.revistasuninter.com/revistasaude/index.php/revista-praticas-interativas/article/view/620

Editora Científica Chefe: Cristiane Cardoso de Paula

Editora Associada: Graciela Dutra Sehnem

\section{Autor correspondente}

Josane Rosenilda da Costa

E-mail: josanerc@gmail.com

Endereço: Rua Martim Afonso, 1335, Bloco D, 201 Jd. Novo Horizonte CEP:87010-411

\section{Contribuições de Autoria}

1 - Josane Rosenilda da Costa

Concepção do estudo, análise e interpretação dos dados, revisão final com participação crítica e intelectual no manuscrito.

\section{2 - Diéssica Roggia Piexak}

Revisão final com participação crítica e intelectual no manuscrito.

\section{3 - Fátima Helena do Espírito Santo}

Revisão final com participação crítica e intelectual no manuscrito.

\section{4 - Stefanie Griebeler Oliveira}

Revisão final com participação crítica e intelectual no manuscrito.

\section{5 - Rosane Gonçalves Nitschke}

Revisão final com participação crítica e intelectual no manuscrito.

\section{6 - Sonia Silva Marcon}

Concepção ou desenho do estudo/pesquisa, análise e/ou interpretação dos dados, revisão final com participação crítica e intelectual no manuscrito.

\section{Como citar este artigo}

Costa JR, Piexak DR, Santo FHE, Oliveira SG, Nitschke RG, Marcon SS. Perceptions of nursing professionals from a general hospital about Reiki intervention. Rev. Enferm. UFSM. 2021 [Cited: Year Month Day]; vol.11 e67: 1-18. DOI: https://doi.org/10.5902/2179769264279 